\title{
Students' Engagement Patterns during Mathematics Classroom Practice
}

\author{
Iliya Joseph Bature \\ Department of Corporate and Information Services, Charles Darwin Centre, Darwin, Australia \\ Email: ijbature@yahoo.com
}

How to cite this paper: Bature, I.J. (2020) Students' Engagement Patterns during Mathematics Classroom Practice. Open Access Library Journal, 7: e6695. https://doi.org/10.4236/oalib.1106695

Received: August 7, 2020

Accepted: September 5, 2020

Published: September 8, 2020

Copyright (๑) 2020 by author(s) and Open Access Library Inc.

This work is licensed under the Creative Commons Attribution International License (CC BY 4.0).

http://creativecommons.org/licenses/by/4.0/

\begin{abstract}
This paper sought to investigate students' engagement patterns during mathematics classroom practice. Four research objectives were designed to guide the discussion in the paper. The qualitative case study approach was adopted to collect data from twelve Senior Secondary one and two students from two secondary schools in Nigeria for the study. Four mathematics teachers taught mathematics for a period of 15 weeks span across three years. A thematic narrative approach was adopted as a tool to analyse the data collected from the students. The results of the study suggested that, six different engagement patterns were observed by the students as present during their classroom practice. The students identified these patterns as teacher-centred engagement pattern, student-individualised engagement patterns, teacher-student engagement pattern, student-students engagement pattern, group engagement pattern and whole class engagement pattern. However, the findings of the study suggested that, four out of the six engagement patterns should be encouraged during classroom instruction. These engagement patterns are teachers-students, students-students, group-based and whole-class engagement patterns. It was also recommended that teachers who pay more attention to the teacher-centred and student-individualised engagement patterns during classroom practice should seek to create classrooms environment that will promote students' positive engagement during mathematics classroom practice.
\end{abstract}

\section{Subject Areas}

Education, Information Science

\section{Keywords}

Engagement, Students, Pedagogies, Teaching Strategies 


\section{Introduction}

There has been a drastic reduction in the standard of students' performance in mathematics at all levels of education in Nigeria in the past two decades [1] [2]. Research evidence of mathematics classroom practice in Nigeria suggests that this fall in students' performance in mathematics is rooted and traceable to the instructional strategies employed by mathematics teachers [2] [3]. The major debates for this student's unsatisfactory performance in mathematics can be traced to the quality mathematics classroom instruction provided by mathematics teachers [4] [5]. This is sometimes as a result of the monotonous mathematics symbols, and formulas mathematics teachers used [6], instead of building their mathematics classroom instruction using the real-life related situations [4] [7] [8].

Similarly, evidence abounds in literature across Nigeria libraries suggests that, the general pattern of mathematics classroom practice in Nigerian revolves around the teacher-centred epistemology [9] [10]. Students' voices and the social justice principles of equal participation of all in mathematics classroom practice are mostly discarded [2] [5] [8] [11]. It is clear from these arguments that, educators and researchers on Nigerian mathematics classroom practice, have also repeatedly acknowledged the fact that these inconsistencies in students' performance in mathematics can also be traced to the passive and strict classrooms practice mathematics teachers employed during their classroom instruction [10] [12] [13]. Glaring evidence also abounds in literature that Nigerian students struggle in classrooms task that requires higher order thinking specifically in concepts that require the demonstration of their knowledge, understanding and competencies [5] [14].

Research studies in Nigerian mathematics classrooms suggest a consistent picture of widespread low-level and passive engagement of students in mathematics classrooms. This sometimes degenerates into students' disruptive behaviours. These disruptive behaviours are not just noise making during classroom instruction, but surprisingly a number of these students become quietly disengaged [6] [15]. There is little agreement in literature as to why such disengagements are observed among students in mathematics classrooms; however data and findings of most research in Nigerian mathematics classrooms point to the fact that students are bored, they are finding mathematics computations too difficult and frustrating [3] [15], the authoritarian monopolistic mathematics classrooms environment created by mathematics teachers is also not helping matters [1].

However, it is important to note that students learned mathematics better, when, mathematics teachers create classrooms that are favourable for students to construct their own mathematical knowledge and understanding [7] [11]. This sometimes can only be achieved when they are encouraged to examine, represent, transform, solve, apply, prove and communicate their understanding in the community of their peers [3] [15], and in a free and fair classroom at- 
mosphere created by mathematics teachers to promote social justice, and void of unnecessary tension [16] [17]. One important strategy that could influence student's positive outcome in mathematics, is creating classrooms that encouraged student's engagement during classroom practice [17]. This suggests that to influence students' positive outcomes in mathematics, student's engagement most be taking seriously. To achieve this, mathematics teachers must be trained and equipped to adopt pedagogical strategies that would enhance student's engagement and participation in profitable mathematics classroom practice [18] [19].

In reviewing the work of Humphreys et al. [20] and Okebukola and Ogunniyi [21], Ifamuyiwa and Lawani [22] identify three patterns of students' engagements that could be demonstrated during mathematics classrooms practice. These patterns were described as cooperative, competitive and individualistic engagement patterns. In cooperative engagement pattern, Ifamuyiwa and Lawani [22] described it as that engagement pattern where students learn together and engage in positive problem-solving opportunities in a community of their peers. This engagement pattern provides opportunity for dialogue, debate, sharing of ideas, and supportive classroom environment void of distraction, diagnosing one another thoughts collaboratively, and creating challenging mathematics problems that cannot competitively or individualistically resolve [10] [22].

In competitive engagement patters, Ifamuyiwa and Lawani [22], described the patterns as a situation where students strictly and independently engaged with their learning materials. In this pattern, there is no room for discussions, sharing of ideas and dialogue with colleagues or any form of support [23]. It is commonly referred to as "the survival of the fittest where the brave wins the race" as each student is expected to work independently to outshine others and only discuss with their teachers, when they run into trouble (Ifamuyiwa \& Lawani [22]). Ifamuyiwa \& Lawani, [22] described the individualistic engagement pattern as the situation where students work individually. This engagement pattern provides no room for support and assistance from anybody (not even the teacher)+, except when the teacher gives general instruction before the task is given, or when all problems are marked and the teacher decided to provide general feedback [10] [24] [25]. In individualistic engagement patterns, weak students are sometimes left unattended to, others become frustrated, distractive and obviously make classroom environments unconducive for learning [10] [25].

Research studies on fostering effective classroom or student's engagement suggest that, creating challenging and interesting classroom environment that would encourage student's engagement in problem solving should be a priority to mathematics [3] [26]. Education researchers, school administrators and indeed mathematics teachers need to take this more seriously, particularly in $\mathrm{Ni}$ gerian mathematics classrooms [3] [18]. There must be positive and deliberate effort from all stakeholders of education to make sure mathematics teachers create classrooms atmosphere that encourages the spirit of critical thinking, 
self-construction and reconstruction of meaning and knowledge in an atmosphere free from tension, fear and mathematics phobia [1] [8] [27]. These classrooms should be far beyond providing materials that encourage simple recall or the use of algorithm [19] [28] [29], or the memorisation of symbols, formulas [6]. Mathematics teachers are expected to pose questions that do not only stimulate students' innate curiosity, but problems that encouraged further investigation with the view of projecting in students a positive attitude towards mathematics engagement [25] [30]. It is belief that, through these mathematics teachers will gradually and constantly build in students the sense of self-efficacy, self-dependence and self-confidence [26] [31]. Students will actively be engaged in problem solving through the investigation of meaningful real-world related mathematics problems [5] [7] [19] [32].

This suggests that engagement in mathematics classrooms is not a static monotonic field of textbook problems, or formula directed problem solving classroom environment. But, it is a classroom environment that is dynamic and student-centred, a classroom environment where students are engaged in constructing meaning about the world around them, a classroom environment where students are generating new knowledge and demonstrating understanding about their real world in a non-threatening atmosphere where collaborations, dialogues, and debates of students thoughts prevailed [3] [12] [33]. And a classroom where students are encouraged to engage in higher ordered thinking. This is achieved, through engaging students in effective collaboration in problem solving with their peers.

It is important to note that, an excellent mathematics program requires teachers to provide effective teaching and learning that will engage students in meaningful dialogue through collaborative engagement [3]. These collaborative engagements promote student's ability to make sense and develop meaning of their mathematical ideas and reasonings, have control over their learning and develop a sense of efficacy in their mathematics problem solving [8] [11] [34]. In view of these, it is suggested in literature that, to provide quality classroom instruction that will foster effective engagement among students, and encourage students self-construction of knowledge as upheld by the constructivist epistemology, there is the need for teachers to provide tasks that has high cognitive demand and that requires multiples ways of providing solutions to them [11] [35] [36]. Such high cognitive task according to Bature and Atweh [3] will compel students to engage in profitable dialogues, debates, thinking through, and seeking support from members of their classroom community. In such classrooms, students adopt collaborative approach to thinking on the right approach and strategy to finding solution to their problems and not the individualistic monopolistic teacher-dictated approach that had left most of our students frustrated and disengaged [3] [12] [23].

However, as good as engagement in mathematics classroom is, it is saddened to note that this only exists in literature as far as Nigerian mathematics class- 
rooms is concern [1] [5]. This is because, there are beautiful research articles, policy documents that support and suggest the implementation of this classroom strategy in most Nigerian libraries. However, these are mere documents meant to obtain promotion as university lecturers, or policy statements stored in the government offices. For example, research study of Nigerian mathematics classrooms suggests that, teaching of mathematics is characterized by the traditional formula-based approach with emphasis on computation, and rote learning [5] [18], with little reference to mathematical reasoning, problem solving, creative thinking or the provision of an atmosphere of student's engagement [26] [37]. Bature and Atweh [11] and Bature and Atweh [25] assert that the absence of effective engagement during mathematics classroom instruction in Nigerian is a case of concern. Research results on Nigerian mathematics classrooms also suggest that even when mathematics teachers attempt creating classrooms that one could look and say students are engaged, such classrooms seem to be casual, teacher dominated, and students individualised paper-pent engagements. Such classrooms lack in-depth quality to foster effective mathematization among students [2] [11] [25].

Therefore, if mathematics teachers in Nigerian classrooms hope to achieve quality classroom teaching, combat the poor performance of students in mathematics and improve students negative attitude to mathematics, there is an urgent need to encourage effective engagement through creating classrooms that are interactive, collaborative, full of discursions, debates, dialogue, negotiations of views and understanding among students in a non-threatening and non-authoritarian classroom environment [27] [38]. Such teachers should develop strategies that will encourage critical thinking, critical analysis of issues, and a democratic classroom atmosphere that encourages exchange of ideas and opinions among students [39]. This paper therefore seeks to investigate the classroom engagement patterns that should be observed in a Nigerian mathematics classroom with the view of decomposing the traditional teacher-centred epistemology in Nigerian mathematics classrooms. The following research objectives guided the study

- To investigate the initial reaction of students on the concept of classroom engagement during mathematics classroom practice.

- To investigate strategies mathematics teachers employed to foster classroom engagement among students.

- To investigate the perception of students on the general pattern of classroom engagements that could be observed during mathematics classroom practice.

- To investigate the perceptions of students on the benefits of classroom engagement during classroom practice.

\section{Methods}

\subsection{Introduction}

In this section, the researcher discusses the design of the study, the participants 
and their selections process, the instruments and the instrumentation, the workshops and interventions provided, the credibility and the validation of the data, the ethical issues and the strategies adopted to analyse the data collected.

\subsection{Design}

A qualitative case study approach was adopted to seek information for this study. Baxter and Jack [40] define qualitative case study as a research methodology where tools are provided for researchers to study complex phenomena in their respective context. This methodology becomes a valuable approach to research if researchers approach it with a high sense of responsibility. Through this epistemology, theories are underpinned, programs are evaluated, and interventions are developed to foster effective classroom instruction. In line with the philosophy of Baxter and Jack [40], the study was developed with a view of investigating effective strategies that would be used to create classrooms that will replace the teacher dominated instructions.

\subsection{Participants}

This study was a subset of a broader study that made use of teachers and students as source of data. However, in this paper, the views of students will be analysed in research objectives 1,3 , and 4 . While research objective 2 , will include some data collected from the views of the mathematics teachers. Since the study was designed to understanding the perception of students on their engagement pattern during mathematics classroom instruction. Four mathematics teachers (Ibrahim, Abubakar, Tanko and Bilhatu) taught mathematics in two secondary schools in Northern Nigeria for a period of 15 weeks spread over three years. The characteristics of the teachers revolve around their years of experience in teaching mathematics. Their average year of experience was seven years. They were all university graduates in mathematics education. Similarly, a total of 12 students were selected to discuss the patterns of their engagements during the classroom instruction of the mathematics teachers. The characteristics of the students selected were from two science classes and one arts/social science class purposively selected for this study. These students were purposively selected to participate in the study suggesting that there was not any form of randomisation. Only the students that volunteered to participate were allowed. In the selection we had two senior secondary one class (15-year-old) and one senior secondary two class (16-year-old). Similarly, there were six boys and six girls making three each from the two sample schools. The students were Pseudo-named; Aminu, Jacob, Jafaru, Jamilu, John, and Joel, (boys) Amina, Bosam, Jamila, Sally, Sarah and Sim (girls).

\subsection{The Interventions and or Workshops}

Given that student engagement and its patterns is a new concept of classroom practice in Nigeria, there was the need for the researcher to provide the partici- 
pants with some information on the concept of engagement and how it can be demonstrated in the classroom. Therefore, before the research started, the researchers had to provide an intensive one-week workshop to help the teachers and the students acquaint themselves with the concepts of classroom engagement. The researcher also continued to provide support to the mathematics teachers and the focus group students throughout the study.

\subsection{Instrument and Instrumentation}

Four instruments were developed by the researchers as tools for collecting data for this student. These instruments include the reflective interviews with the mathematics teachers. The classrooms observations of the classroom teaching observed, the focus group interviews with the 12 focus group students, and researcher's research journal. The brief descriptions of each of the instrument are discussed below.

\subsubsection{The Classroom Observation}

The researcher adopted classroom observational strategy to obtained data for the study. These were both in-class observation of teachers and students practice and the out-class observation of the interaction of the teachers and students on the concept under study. The in-class observation was used to measure behaviours of both teachers and students during classroom instruction. This constitutes the actual engagement demonstrated by the students during the classroom practice. In the two schools under study, there were 3 lessons of 40 minutes and one lesson of 80 minutes per week. There were 8 recordings of the classroom practice of the teachers and the students. However, the researcher kept a research journal to record other observations throughout the fifteen weeks. The out-class observations were used to measure the questions and answer sessions with both teachers and students or during the research. All actions related to the research objectives were captured both in writing and in video recording.

\subsubsection{Reflective Interview}

There was a two-hour reflective interview after every three weeks of teaching, the researcher and the mathematics teachers met and review the teaching and discussed their weaknesses and strength before launching into the next three weeks. Most of the support the researcher provided were done generally during the reflective interviews. There was a total of four reflective interviews with the mathematics teachers. The findings and comments of the teachers in this study would serve as response to research object 2 of the study. We are using the teachers' voices or views to determine the support they received and what strategies they adopted to achieve effective engagement in their classroom instruction.

\subsubsection{Focus Group}

The twelve students selected were invited for a focus group discussion after every three weeks of teaching. This was made up of four focus group interviews. There were three focus group interviews in the first school and one focus group 
interview in the second school. The first School had 10 weeks of teaching and data collection every 3 weeks. The second school was used as follow up where teaching and data collection lasted for 5 weeks. These students would meet with the researcher and discussed the patterns of engagement their mathematics teachers created during their classroom practice. This constituted the major data used for this article. Hence the data was used to answer research objectives 1, 3, and 4 .

\subsubsection{Research Journal}

The researcher also kept Research Journals to record all other observations that were not captured by the video recorder. This instrument was used with the view of obtaining credibility and for triangulations. There were discussions the researcher had with students outside the focus group meetings that were not captured during the classroom instructions. This information was useful and hence constituted important information for this study. Such observations and discussions were kept in the researchers' Research journal.

\subsection{Ethical Issues}

The researcher obtains relevant ethical permission from the school to carry out the research. Since the research was conducted with minors, the principal sends consent forms to the parents of the affected students, and they gave their permission in writing to the principal before the research commences. The content of the consent was also read to the students to ascertain their willingness to participate in the research, their rights and responsibilities were also read to them by the researcher through the principal before they were made to sign the consent forms. Relevant consents were also obtained from the mathematics teachers and their principals. It was clearly explained to all the participants that they are free at any time of the research procedure to withdraw their participation, if the study will infringe into their rights, or they are no more comfortable to participate in the study. Due to confidentiality issues, the consent forms of both the students and their teachers were kept confidential and hence cannot be attached to this article.

\subsection{Credibility and Validation of the Instruments and Data}

Several techniques were adopted by the researchers to validate the instruments used in collecting data for this research. The first step of ensuring the validity of the data collected was choosing a well-trained and skilled moderator or facilitator to look at the quality of the data collected. This was done by an associate professor in Mathematics Education in one of the universities in Australia. The Colleagues who were Lecturers in the Faculty of Education in Nigeria where the researcher was a lecturer also validated the data collected. In the faculty of education. This was done by a senior academic in the faculty of education. The moderators checked personal biases and expectations of the research. While a good moderator is key, another strategy adopted to validate the data is the 
choice of the sample group. The participants were truly members of the segment from which they were recruited. The researchers also employed ethical recruiting to collect data from mathematics education specialist who were truly representative of their segment, teaching mathematics to a set of senior secondary one (15 years) and (senior secondary two (16) students. Through these, the researchers believe it will lead to achieving a valid result. The researchers also employed triangulation strategy to validate the data by adopting multiple perspectives of using several moderators, and different locations with the view of getting the results from different angles. The respondent validation strategies were also used, where deep saturation into the research with the view of promoting credibility and validity of the data collected. Finally, the researchers sought an alternative explanation of ideas from the participants as a means of obtaining credibility of the data collected.

\subsection{Data Analysis}

Data analyses in this paper concentrated on the focus group interviews and the observations of the mathematics teacher's classroom practice and the researcher's Research Journal on the perceptions of students on the engagement patterns that play out during their classroom practice. The narrative approach was adopted to analyse the data collected through reflective practice of the focus group students on their patterns of engagements. This agrees with Clandinin and Connelly [41] who were of the view that narrative could be used in analysing research data that the researcher might have recorded, or a story through a journal, diary or that the researcher might have observed individuals and records fieldnotes during data collection. During narratives, researchers seek to identify themes, categories, and patterns in order to determine relationship between the themes identified and the response of the subjects to the research questions [42]. After which the researcher will begin to make meaning with the data collected through a process of rigorous and constant comparisons of related themes [42] [43].

While conducting qualitative research, researchers collect large chucked of data, either through observations or as in this case, through focus groups interviews. After the data were collected, the researcher would sit down and watched the videos, transcribed all that was recorded into a written document. After this process the researchers read through the transcripts and begin to group the ideas into themes, codes and patterns, with the view of making meaning of the data. Research studies suggest two approaches to thematic analysis [42]. The researcher could decide to use inductive thematic analysis which allows the data to determine the themes to be used or a deductive analysis where the researcher comes to the data with some preconceived themes [42] [44] [45]. In this paper, the researcher adopted both the inductive and deductive themes approach to the data analysis. In data analysis themes are majorly, the key words used to group the data into reasonable patterns or codes. Therefore, the data collected were 
codded and all the codes were sorted into different themes by grouping the focus group students' comments, views and perceptions into related patterns. After which, the researcher began to make meanings with the themes through the process called analysis or as called by Caulfield [42] "Thematic Analysis".

\section{Results}

\subsection{Introduction}

This section constitutes considered the following themes as the researchers seek to respond to the four research objectives created. First, the researchers discussed the initial perceptions of the students on the concept of engagement played. Second, the researchers discussed the perceptions of teachers and students on the strategies the adopted to foster effective engagement during their classroom practice. Third, the researchers discussed, the different engagement patterns demonstrated by the students during their classroom practice. And finally, the researcher discussed the benefits obtained from the introduction of the concept of engagement as a teaching strategy in their classroom instruction.

\subsection{The Initial Reaction of Students on the Concept of Engagement}

Research Objective 1. To investigate the initial reaction of students on the concept of classroom engagement during mathematics classroom practice.

The initial fear of the researcher, the mathematics teachers and the students at the beginning of the study was that the students may use the concept of engagement in their classrooms to cause distraction during classroom instruction. These students greeted the introduction of engagement into their mathematics classrooms practice with mix feelings. One of the students murmured with his friend when the mathematics teachers were trying to organise their classes at the beginning of the study.

This is a mission school, the school authority is strict and firm against any male-female relationship..., we are also made to believe that, there should be some restrictions in our relationships. Therefore, making us sit together with boys..., talk together (though in groups) seems a new thing altogether... this indeed, is very strange..., (Bosam; Research Journal)

Yes Bosam...its very strange..., I thought we have been taught that when problems are given in the class we should cover our work or we should not allow anybody to see what we are doing..., but asking us to work together looks strange..., I feel this is morally wrong..., it's like these teachers did not know that this is a mission school..., but..., our teachers were with them..., they even encourage and supported the idea..., it is strange..., (Sarah: Research Journal).

From the initial thinking of Bosam and Sarah, it suggests that students in most Nigerian schools have been indoctrinated to view engaging students into effective classroom talk on the problems solving activities is morally wrong. It is good to clarify here that engaging students in classroom talk during classroom in- 
struction cannot be view as examination malpractice. This is because, such discussions are not done during a writing examination. The researchers clarified these perceptions to students particularly Bosam and Sarah during the workshop and again during the focus group interview.

Data collected during the study also suggested that the initial perception of the students was that the concept of engagement could bring distraction and disruption of classroom instruction. However, the perceptions of students towards the end of the research suggest a philosophical change from their initial perceptions. This suggests that effective engagement in problem solving will help students to be busy in their classroom activities. It is suggested that "an idle mind is restless, but a busy mind is active". This suggests that classroom engagement did not give students opportunity to cause any form of distraction or disruption of classroom activities.

I initially thought this will fail, because, what we know and see our maths teachers do is to do all the talking..., I thought asking us to discuss the maths problem with our mates will make the class distractive ... but, I discovered the class was too busy..., I can see students in groups working together to find solution to the problems..., I learnt more from my classmates also..., especially as you know..., mathematics is a very difficult subject..., (laugh...,) (Amina, Focus group)

Hmnn ..., my first thought was that the class will be distractive and noisy..., but it seems the teachers were very Smart, active and good..., we had no opportunity to do other things..., it worth having to discuss mathematics problems with my colleagues (Jamila: Research Journal)

The perception of Jamila and Amina suggests that the students were so engaged and hence had no time for idle talk, and hence no room for any form of distraction during the classroom practice. This perception suggests that effective and productive engagement during mathematics classroom instruction could be a tool mathematics teachers could use to help control student's disruptive behaviour during classroom practice. Data collected in this study suggested that the secret behind the effective and productive engagement in mathematics activities is that, the mathematics teachers strengthening their pedagogy. Jamila supported this by asserted that,

Sir, the truth is I never believe all that you were saying during the workshop..., I cannot see students working independently without our teachers giving us the formula, solve many examples etc..., but when we started..., slowly, slowly, the mathematics teachers became experts..., it seems they were very smart, active and good..., we had no opportunity to do other things..., it worth having to discuss mathematics problems with my classmates. (Jamila: Focus Group)

That is true Jamila..., I concurred..., it seems after the first three weeks and our meeting..., it seems the mathematics teachers when for further training, because they came back strong..., and shelved most of their authoritarian way of 
doing thing..., (Joel: Focus Group)

Hmnnnn Joel..., This is the first time you say something reasonable, (Sarah: Focus Group)

Sarah what do you mean...? Hey..., Bossam Warn your friend..., (Joel; Focus group)

Sincerely sir, this time I agree with Joel $100 \%$, the teachers were prepared, very good, ..., they got all of us busy..., we were all involve in the classroom work..., Joel..., Am sorry..., But you argue a lot..., you have been dragging us back..., but this time ..., I give it to you..., The teachers were good and well prepared. (Sarah; Focus Group)

From the initial perception of the students on the concept of engagement, it suggests that the students had their doubts on the effectiveness of their mathematics teachers creating classrooms that are engaging. The data from the study also suggested that the mathematics teachers struggled in the first three weeks. Perhaps, the reasons are not far from the perception of Joel who stated that "The teachers shelved most of the authoritarian way of doing things". And the fact that the teachers were prepared and made up their minds to have a change in their classroom practice.

\subsection{Strategies Mathematics Teachers Used to Foster Classroom Engagement among Students}

Research Objective 2. To investigate strategies mathematics teachers employed to foster classroom engagement among students.

Data collected in this study, suggest that, the mathematics teachers adopted some strategies to foster effective engagement during their classroom practice. From my observation this was not easy from the part of the teachers that are used to dictatorialism. The workshop session provided the teachers and students with most of the support they needed to set the stage rolling. However, the reality down on them when the actual research started. From observations, the first three weeks of the research was like the preparatory stage of the study. The teachers struggled to shelve their dictatorial attitude to classroom instruction, thereby creating apprehension among students. Particularly those who were at the workshop. They saw something different from what the researchers taught them during the workshop. During the first focus group meeting with the students, then the reflective meeting with the mathematics teachers, a lot of support and scaffoldings were involved in helping the teachers adjust to the new epistemology. The teachers asked a lot of questions on the way forward. There were a lot of criticisms from the students too. For example, one of the mathematics teachers during the reflective interview asserted that

Sir, when the teacher is in the class, he is supposed to be in control of all the activities. He should be in-charge of directing all the affairs of his class, allowing students to take control of the classroom activities might be counter-productive. (Tanko: Reflective Interview) 
The truth is that for effective teaching, (in my view), the mathematics teacher must dominate and control the classroom activities. If not sir..., one will find it difficult finishing what he has prepared for the class..., and you know is frustrating for a teacher to prepare a lesson and could not teach it..., (Bilhatu: Reflective Interview)

The truth is ..., in our society, if you want the best from your students, you need to handle them with iron hand (Ibrahim: Reflective Interview)

The comments of Tanko, Bilhatu and Ibrahim above suggest what actually operates in the typical Nigerian mathematics classrooms. The mathematics teachers always want to show that they are in charge and students are to obey them all the time. In defending their view also, the mathematics teachers asserted that students take pleasure depending on them and or working independently instead of being engaged with their classmates. For example, Ibrahim asserted that

My students tend to prefer working independently. This is against my plans..., I wanted to create a class where students would be engaged..., but when I gave them a problem to solve..., before you know..., they independently, solved the problem for me..., introducing them to classroom or students engagement was very difficult for me..., it looks too complex..., some of them are of the view this is a waste of time and distractive. (Ibrahim: Reflective Interview)

That was not the case in my class..., My students were too dole they did not know what to do..., I wonder if this is possible in a slow learning classroom..., my students are not that intelligent so engagement could have been the best..., but they were delaying my classroom teaching..., (Abubakar. Reflective Interview)

We had a long discussion with the mathematics teachers. One of the agreements reached was to introduce higher ordered thinking problems to manage the students willing to work independently instead of engaging in collaborative talk during the classroom instruction. We also agreed to intensify and increase one-one support. These paid up because of the views of the students. Their engagement increased and they gradually adjusted to the strategy.

Sir..., the questions our teachers gave us were too difficult..., initially..., I thought we could just look at the example and follow the same pattern... But it was not possible to solve..., we argued, we share ideas... We looked at the question again and again..., after much thinking and debating in our group the result came out..., (Jacob: Focus Group)

That is true... that question was too Firebolous (difficult)... Smile... but we solve it... (Joel, Focus Group)

$Y e s, \ldots$, this is because... it is not one person doing the thinking on the way to solve the problem, the thinking is shared in the group. By the time we put our heads together and think on the way forward on a problem..., you bring your idea..., I bring my idea ..., the solution become easier..., (Sarah, Focus Group)

The problem was so challenging that the students had to get talking to them- 
selves and to other group members. They were initially murmuring, these transformed to a more serious talk on the way forward..., With much talk among themselves and the support provided by the teacher, the solution was gotten (Classroom Observation)

To manage the challenge of Abubakar, the mathematics teachers agreed to adopt the grouping strategy to managing students with learning challenges and to force classroom engagement among the students. The mathematics teachers made their students sit in groups and encourage them to share ideas together. Data collected in the study suggested that this created classroom engagement among students and the students with learning challenges received support from their classmates. One of the students had this to say,

We were fixed to sit in groups like in a circular form, and we were made to interact with one another in the class..., it was a bit difficult and strange at the beginning..., but..., as we continued, it became interesting, from what I can say in my group, those of us having problems with maths..., Hmn,..., Smiled..., it encourages us the slow learners ..., sha..., and we were not left out, the good students carried us along. (Amina: Focus Group)

The mathematics teachers got their students engaged..., working on their own..., and in their groups..., I (The researcher) observed the teachers moving around..., providing support and scaffolding to students having challenges..., the students were also moving around to received support and I think to provide support also to one another..., the classes gradually were becoming more and more engaging ..., (Classroom Observation: Research Journal)

Finally, one of the strategies the mathematics teachers adopted to forester effective interaction was Scaffolding and students support. Data collected suggested that the teachers made concerted effort to make learning students-centred, even though they did allow students to control their learning there was a sustained support from the teachers to their students. The students gradually took control of their learning. The teachers were observers of learning rather than dictators of learning. For example, the researcher observed,

From the classroom practice of the teachers it was observed and video recorded that the mathematics teachers got their students working on their own, I observed the teachers moving around providing support and scaffolding to students having challenges..., they were also moving around to see what the students were doing... (Classroom Observation)

The approach was good and interesting..., the mathematics teachers grouped us to sit together to solve mathematics problems..., it was very interesting for us because we did the work on our own without the unnecessary interference from the teachers..., they only assist us on the board and when they discover we are helpless..., (Jamilu: Focus Group)

That is true, Jamilu, we were helped..., supported, the teachers were good..., O observed that the support was not only from the teachers but also from our friends and classmates..., this is good. (Sally, Focus Group) 


\subsection{Patterns of Classroom Engagements Observed by Students}

Research Objectives 3. To investigate the perception of students on the general pattern of classroom engagements that could be observed during mathematics classroom practice.

Data collected demonstrated that the students observed different patterns of engagement during their mathematics classroom practice. From the perception of the students, this article was able to identify 6 engagement patterns as discussed by the students. The first of these engagement patterns was what the students called teacher-students or student-teacher engagement pattern. Even though, it is regarded as one engagement pattern; however the students viewed them as different. In their argument there were of the view that the pattern of this classroom engagement can generally be determined by the person that initiated or leading discussions during classroom instruction. For example, the perception of Jamilu suggests the student's definition of what they termed effective classroom engagement.

Sir, in my view, classroom engagement depends much on who initiated the classroom talk..., this could be initiated by the teacher or by the students...., yes..., by the student. (Jamila: Focus Group)

Yes sir..., Jamila is right..., the pattern of classroom engagement can be determined by the person initiating the classroom discussion (Jamilu: Focus Group)

Hey guys, what do you mean? Can you explain further? (Researcher, focus group interview)

Sir, I think, what Jamilu is saying is that. Classroom engagement that is initiated by the teacher could in my view be termed teacher-students engagement pattern, while the engagement initiated by the students could be term student-teacher engagement pattern.

What is the difference? Sarah, could you explain further? (Researcher. Focus group)

Okay sir..., if a student initiates a discussion with the teacher by trying to defend his view or understanding of a particular problem in maths in a one-on-one basis, I can call that "student-teacher engagement pattern. (Sarah: Focus Group)

Sarah is right sir..., and if the teacher initiates the discussion with the student or with a group of students or even the whole class, this could be by asking ... you mention a word during workshop) ..., ehm... Prob... yes asking probing questions to a particular student or group of students, I believe that is teacher-initiated discussion or engagement..., which I can call teacher-student(s) classroom engagement pattern. So, in my view Sarah and Jamilu are right (Joel: Focus Group)

One can deduce from the perception of the students above, that teacher-student and student-teacher classroom engagement is a pattern of engagement that should exist in an effective mathematics classroom. Using their higher order thinking, the students distinguished between teacher-student engagement 
pattern from the student-teacher engagement pattern. They suggested that, this can be determined by the person that initiated the discussion during classroom instruction. From the discussions above the students were also able to describe both patterns using mathematical argument for example, Joel argued that teacher-student engagement pattern could be determined, when the teacher is asking probing questions and the students battles to respond to them. Supporting Joel's view, John asserted that:

When the teacher came to our group, and discovered that we were struggling, he was asking us some questions..., and we were responding and answering..., before you know, The Idea just click to our brain... and we continued..., I think that is teacher-students engagement pattern..., and it was good..., (John: Focus Group).

To me, there was a good teacher-student (engagement) conversation..., the teacher did he's best in maintaining this engagement pattern in the class, which I believe leads to deep understanding among the students. (Bosam: Focus Group).

As the mathematics teachers were moving around from one group to the other, I observed the students were engaged in profitable discussions in their groups, in almost all the classes I observed, the teachers engaged each group with some form of classroom activities that kept the class engaged and busy ..., the teachers will sometimes move the whole group of about 4 or 5 to the board and asked them some probing or leading questions..., sometimes I will hear them asking similar probing questions from group to group. (Classroom Observation)

In defending their perception of students-teacher engagement, perhaps, one may think that this pattern of engagement is the same with teacher-student classroom engagement. However, the focus group students viewed them differently. They were of the view that this form of engagement is student-initiated. This could be in the form of students asking their teachers questions personally to seek further clarifications or a student defending his or her views in a debate between teachers and students in the class.

Sir ..., there are times we walk to the teacher to clarify our thinking..., I don't mean the whole group..., for example, I was discussing with my teacher..., on my understanding on the approach to finding solution to the quadratic equation problem he gave us..., the approach of the teacher was different from my perception or understanding..., I used my idea of surd and the teacher refused..., I engaged him in a form of an arguments ..., I defended my view and he agreed with me..., that is students initiated engagement..., I was happy I defended myself..., Sarah what did you say? (Joel: Focus Group)

Yes sir, don't mine Joel... in our class, we debated and defended our solutions... and everybody was involved (engaged) contributing his ideas in the class..., the teacher was asking us more questions (Probing) to check our understanding..., that is students-teacher engagement (Sarah: Focus Group)

From my observation in one of the classes, I saw students defending their thoughts before the teacher on a one-on-one basis. The mathematics teachers 
also asked them to justify their solutions (Research Journal)

This pattern of classroom engagement takes the form of students discussing one-on-one with the teacher trying to clarify or justify their claims and position on particular classroom problems. This suggests that, when student-teacher interaction is encouraged during mathematics classroom instruction students understanding and self-efficacy in mathematics increases. Students' self-confidence and attitude toward mathematics and problems solving in mathematics also increases when they are allowed opportunity to defend their views in a student-teacher engagement pattern.

The second engagement pattern described by the students is what they call teacher-centred engagement pattern. From the perception of the students, this pattern of classroom engagement is commonly referred to as teacher-chalk engagement pattern. In this pattern of classroom engagement, the teacher asked the students to sit quietly in the class and listened to him/her dish out instruction to their students. Their role is to listen and only respond when they are asked to. From the perception of the students, during this pattern of classroom engagement, the mathematics teacher faces the board talks to the board while writing, not minding if students are following or not. Some of the comments made by the students on this include:

The discussion was just between the teacher and the board..., the teacher never burthened if we were following or not..., we are willing to talk to one another..., but, the teachers did not allow us talk about the problem first..., but when to the board and give us the solution to copy. (Jamilu: Focus Group)

The teacher was just talking to the board..., (Joel: Focus Group)

So, what was your view about the teacher-chalk engagement? (Researcher. Focus group)

Sir, the teacher was simply facing the board and talking, this only help promote what we have left behind since we started this program, I don't think it's good for students..., Jamilu said..., we were willing to discuss the problem in our groups..., but we were not given the opportunity. (Sally: Focus Group).

That is the fact sir,... one of the teachers was simply working alone, He was just talking and writing on the board. Even when he gave us a problem to solve, the teacher never gave us enough time to discuss the problem, we were not allowed to finish, ... Students were sometimes or all the time (disengaged) not part of the lesson. (John: Focus Group)

From the argument of the students above, it suggests that, these students frowned at this classroom engagement pattern. This is because of its teacher-centred and was of the view that it should not be encouraged during classroom practice.

The third engagement pattern identified by the students during the research is what they described as students individualised pattern. From their perceptions, this engagement pattern was observed at the initial weeks of the research. However, when the research progresses, the student individualised engagement pat- 
tern gradually fade away and was not common among the students during the latter part of the research. From the perception of the students, this engagement pattern is gingered by the general teacher-centred engagement pattern. Defending this view Sarah said,

See sir..., sometimes the mood in your face alone makes people to be attracted or run away from you. If your mood is friendly the students will be willing to listen to you. But when your mood is not friendly, and you tide your face, I personally will be scared of you and whatever you are saying, I will not pay attention to you. I will not enjoy or understand what you are saying as a teacher in the class. (Sarah: Focus Group)

I prefer working independently. I don't like being disturbed by other students, they are lazy, too slow for my liking... I like doing my work a head..., getting involved with other students will delay me... (Bosam: Focus Group)

Hmnn ..., I prefer working alone..., this is because, I sometimes want to contribute something to the discussion in the class, but I sometimes feel what I will say will not be correct and others might laugh at me..., especially boys who claim they know maths..., some people are just too proud to help others..., to avoid such embarrassment, I better try my luck or ask the teachers for assistance (Amina: Focus Group)

From the views of the students above, one could deduce that there are two types of students individualised engagement pattern. First is the individualised engagement pattern coming from exceptional students. They (exceptional Students) believe getting involved in helping other students during classroom instruction could delay their work. Therefore, such students believe engagement with other students in the class is a waste of time to students of high ability.

The second type of students individualised engagement patterns is the one coming as a result of the teacher domineering and unfriendly approach to students during classroom instruction. This mostly affects slow learners, or timid and fearful students who due to fear of being ridiculed or laughed at by their teachers and peers decided to disengage or refusing to contribute meaningfully during classroom engagement activities.

The students-individualised engagement could also be observed among the female students. There is this general belief in Nigeria that mathematics is a masculine related or dominated subject, and sometimes females' students that are good in mathematics are labelled as students with some supernatural powers or ritualistic students. And to avoid being labelled as a witch such female students tend to avoid contributing to classroom instruction.

The fourth engagement pattern from the perception of the student, is what they identify to be called students-student engagement pattern. From the view of the focus group students, even though they enjoyed and appreciated the beauty of teacher-student and student-teacher interaction. They however suggested that the student-student interaction is preferred to all other forms of interactions created by the mathematics teachers. Supporting this view, the students asserted 
that:

Most mathematics classroom instructions I have experienced before now had been the classrooms where we are made to sit quietly in the class and listened to the teachers doing the talking..., but, this classroom setting where we are in groups, doing most of the work on our own, with our teachers providing assistance by the side not like dictating the strategy to follow... Its good... I hope our teachers watching this will learn from this research team and continue with it (Jamila: Focus Group)

Before..., you sometimes find it difficult to understand what the mathematics teacher is saying, and you dare not talk. But this time around..., you have your classmates to work with, share ideas on areas you don't understand. In my view this is good... (Sally. Focus Group)

From the perception of the students, student-student pattern of engagement is that classroom engagement where students are busy working on problems either created by the teacher or created among themselves with little or no interference of the teachers. During this period student initiate their strategies, provide learning support to one another and also received support from one another. Sarah was of the view that

We were busy in our group..., some students from other groups came to our group to seek assistance ..., and we assisted them on the problem given to us. We had little or no assistance from our teachers..., I also had this inner satisfaction, that I contributed to the solution of the problem in our group. (Sarah: Focus Group)

It makes us talk to one another, not on other things as usual, but on mathematics, we were busy working together to find solutions to our common mathematics problems. It makes good (high achieving) students in the class offer some assistance to the low achieving students and thereby encouraged them to work without being frustrated (Bosam: Research Journal).

From the views of Sarah and Bosam above, this approach suggests that for any effective mathematics classroom instruction, student-students engagement pattern is very important and makes mathematics classroom teaching and learning more students centred. From my observation in all the classes I visited, I discovered that, students-students engagement pattern devolves responsibility to the students, as in their groups, they have the responsibility of making sure every member of the group participates in the classroom activities. They also take responsibility of their learning, and that boasted their self-efficacy and reduces the general mathematics phobia among secondary school students in Nigeria.

The fifth pattern of classroom engagement according to the perception of the students, is what they called whole class engagement pattern. The whole class engagement pattern is that engagement pattern that is directed by the mathematics teacher. It is mostly done during the teacher-student engagement pattern. The students appreciated this form of engagement pattern and commented that it helps in building cordial relationship between the teacher and the students and 
it encourages effective discussion during classroom teaching. Jamilu appreciated this by saying,

The mathematics teachers were able to bring the students together and it was like there was effective involvement of the students in the teacher students question and answer session..., all the class were enthusiastic during the classroom activities. (Jamilu: Focus Group)

These teachers (mathematics teachers) were smart, the adopted a question and answer techniques to get al the students in the class working, we talked to them, to ourselves, in fact there was so much to discuss that we had no time for distraction. Every student was busy (on task) (Jamila: Focus Group)

From the view of the students above, it suggests that whole class engagement creates opportunities for students and the teachers to blend together. The general teacher bossy relationship with students is broken and students relates freely with their teachers. I can deduce again from the view of the students that the whole class engagement is generally fostered by the question and answer sessions during classroom instruction.

The final engagement pattern observed by the students is what they call group-based engagement pattern. From the perception of the students, even though, the whole class engagement was appreciated by the students, because it created opportunity for students to blend in relationship with their classroom teachers, the students identified another form of engagement which they called group-based engagement pattern. Data collected by the student suggest that they preferred the group-based engagement pattern to that of the whole class engagement pattern.

We interacted within our groups and outside our group..., so beautiful... what I mean is this ..., within our group... is when we interacted with members of our group, we discuss the problems together, share ideas within the group..., while without the group is when we go out to other groups to give or seek assistance from colleagues. (Jacob: Focus Group)

Group based engagement breaks the class into smaller units and students discuss their views and ideas in small groups, ideas are shared, individualized needs are commonly and easily identified within the groups and met without the unnecessary interference of the teacher. (Jamila. Focus Group)

The group based engagement created opportunity for effective interactions or conversation (whatever you want to call it) Smiled..., I mean ..., we interacted in our group..., some students from other groups came to our group to seek assistance ..., and we assisted them..., (Sarah: Focus Group)

I observed that the problem was challenging..., hence, forced the students to be engaged in intensive dialogue within their groups..., The teacher also encouraged them further by suggesting they could seek assistance from other groups..., interactions within groups and outside the groups were intensified, the class became interactive, dialoguing, while negotiations, debates and collaborations were intensified among the students..., I could see every one busy..., 


\section{(classroom Observation)}

From the perceptions of the students above one could deduce that group base engagement pattern creates opportunities for students to work in small groups, share ideas among their colleagues, give and received help from one another and created opportunity for students to defend and criticised one another thoughts in a community of practice.

\subsection{Benefits of Classroom Engagement during Mathematics Classrooms Practice}

Research Objectives 4. To investigate the perceptions of students on the benefits of classroom engagement during classroom practice.

The analysis in this section looked at the benefit of creating mathematics classroom the employed students' engagement. Data collected suggested that the classroom engagement created by mathematics teachers makes mathematics classroom instruction, interactive thereby make students learning interesting. This suggests that engagement in mathematics classrooms makes classrooms practice interactive, thereby helping students find their learning more interesting, and perhaps, help them overcome the negative attitude of students to mathematics and mathematics teachers that had bedevil the Nigerian mathematics classroom. Similarly, from the perceptions of the students, classroom engagement brings students together, build teacher-students' relationship and also strengthen students-students relationship. Effectible classroom engagement from the perceptions of students above helps remove the fear of mathematics generally observed among students.

The mathematics teachers make the mathematics classroom practice very interesting, students were interested and pay close attention to what the teacher was doing in the class..., they were also very involved and the mathematics teachers encourage us..., this made our classroom practice more students focus and engaging..., we all encourage to work together..., it was good..., (Joel: Focus Group)

Solving mathematics problems with our colleagues give us the opportunity to ask questions without fear..., unlike when the teacher controls everything..., it was so nice..., we maintained this conversation in the class throughout, it helps my understanding of mathematics better... (Bosam: Focus Group)

I wished my teachers continued with this; because since we started this work, we solve problems together in the class, in the hostel and even during prep in the evening..., I discover mathematics is a bit easier when you work with your classmates than when you are alone. (Jamila: Focus Group)

The approach brings all students together to see a mathematics problem as a group problem not as an individual problem. The approach was very interesting, we sit in groups to solve the problems together, (Jasmin: Focus Group)

This is not one person doing the thinking on the way to solve the problem, the thinking is shared in the group. By the time we put our heads together and think on the way forward on a problem..., you bring your idea..., I bring my idea ..., 
the solution become easier..., (Sarah, Focus Group)

From the perception of the students, the student-students engagement pattern and the whole-class engagement pattern brought the students and their teachers together to build the teacher-students relationship and it also brings students together in building the students-students relationship. This perception suggests that the general barrier between students and their teachers is removed or bridged. Students can now go closed to their teachers at any time to seek assistance on mathematics issues that concern them, the teacher also through these classrooms' patterns know more of their students' abilities and needs. In this type of classrooms there is freedom of expression among students, the students were also able to ask their colleagues questions without fear, and that help their understanding, built their confidences and created an atmosphere of friendship.

Another benefit of classroom engagement from the perception of the students, is the fact that group-based engagement pattern provides opportunity for the gifted and the slow learners work together. It helps the slow learners learn from their colleagues with little or no fear of asking questions from colleagues.

We were fixed to sit in groups like in a circular form, and we were made to interact with one another in the class, that encourage the slow learners and they were not left out, they were carried along. (Sim: Focus Group)

Sir am serious..., you can challenge the view of your colleague, argue with your colleague..., one has the opportunity to defend his/her view with his/ her colleagues also..., but with your teachers... Sir..., you dare not ..., (smile...) don't you think so? you try it with my maths teachers ..., Hmn ..., she will keep you out of maths class for one week..., cutting grasses outside... (Sarah: Focus Group)

This suggests that effective classroom engagement removes the fear of being embarrassed or humiliated as claimed by Amina in the student individualised engagement. The effect of this classroom engagement during mathematics classroom instruction encourages the slow learners; the high achieving students all work together to share ideas and help one another in solving the mathematics problems. Similarly, from the perceptions of the student's effective classroom engagement increases student understanding, and help students engaged in debates, arguments the opportunity to defend their views thereby claimed ownership of the knowledge acquired.

\section{Findings and Discussions}

\subsection{Introduction}

It's generally believed in literature that: Nigerian mathematics classrooms adopt the teacher-centred approach to instruction. In these classrooms, teachers own the knowledge, control and dictate the way such knowledge is disseminated and also dictates the affairs in the classrooms [12] [30]. Students' responsibilities in such classrooms are to sit quietly and listen carefully to the teacher dish out such knowledge or instruction to them. They only act when they are asked or autho- 
rised by the teacher to speak. These findings negate the views of Brophy [46] and Dele-Ajayi et al. [5] who see mathematics classrooms in a constructivist perspective and argued that, an interactive mathematics classroom is that classroom where mathematic teachers create communities, and students are giving opportunities to create shared understanding in an atmosphere of dialogue, debates and negotiations etc. in such mathematics classrooms emphases are shifted from the teacher-dominated classrooms to a more student-centred pedagogies [5] [9].

\subsection{The Initial Reaction of Students on the Concept of Engagement}

The findings of the study suggested that the students greeting the creation of classroom engagement patterns with some mix feelings. One of their major concerns was that introducing classroom engagement in Nigerian mathematics classrooms could generate distractions from the unserious students. This agrees with the findings of Attard [47] and Emaikwu, [2] who believed that when students are engaged with mathematics and other influences such as poor pedagogy, lack of confidence and negative influence from peer come to play, such students could be disengaged during classroom practice. However, this disagrees with the findings of Seah and Anderson [19] and Sullivan [26] who believes effective motivation by mathematics teacher during classroom engagement will foster effective classroom practice among students.

The findings of the study also suggest that, encouraging engagement among students during mathematics classrooms practice where students will share ideas and understanding with one another is unethical, because, they have earlier been taught that students should work independently without seeking assistance from others. However, this perception of the students changed as the study progresses. There perceptions and views about classroom engagement and sharing ideas with their colleagues changed as a result of the mathematics teachers' change and strengthened their pedagogies [2] [47].

However, the student's perception changed when they research continues as they were able to learn more and faster from their colleagues, suggesting that effective problem solving and collaboration among students can best be achieved when mathematics teachers create classrooms that are engaging and students centred [3] [11]. Similarly, classroom engagement during mathematics classroom instruction provides opportunity for students to dialogue, debate, share, support and diagnose collaboratively challenging mathematics problems that they cannot competitively or individualistically solve [11] [22].

\subsection{Strategies Mathematics Teachers Used to Foster Classroom Engagement among Students}

The findings of the study suggested that, the mathematics teachers gradually developed confidence, skills and strategies to achieve classrooms that foster effective students' engagement. Prominent among their strategies was the introduc- 
tion of a more relax classrooms where the students take more responsibility for their learning. This could also be viewed as the student-centred learning approach. This agrees with the constructivist principles suggested by Bagger and Roos [4] that, student learned how to learn, when teachers give them the opportunity to take initiative or are trained to take initiatives to discover principles, concepts and facts for themselves. Closely related to the relax classrooms was the introduction of the grouping system. The mathematics teachers put the students to sit in groups and encouraged them to interact with one another while solving problems. Suggesting that changing the classroom environment to improve students' engagement can contribute to the favourable students' attitude to mathematics [27] [48].

Another strategy adopted by the mathematics teachers was the introduction of the highly challenging problem, to forester effective collaboration and interaction during classroom instruction. The findings suggested that, students with high ability tend to prefer to work independently compared to students with low ability. It was however discovered that when the mathematics teachers provided challenging problems, students were engaged in profitable discussions to find solution to the problems. This suggests that, providing high cognitive task to students during problem solving exercises compelled students to engaged in profitable dialogues, discussions and interactions with members of their classroom community [11] [35] [36].

\subsection{Patterns of Classroom Engagements Observed by Students}

The findings of the study suggest that the students were able to identify six engagement patterns that could be seen during mathematics classroom instruction. These engagement patterns from the perceptions of the students could be determined by the initiator of the engagement. From the students' perspectives, there are situations where the teacher initiates the classroom engagement which they called teacher student engagement and at some cases student initiate classroom engagement which the called student-teacher engagement. Some of the engagement patterns observed by the students during the study include the following.

\subsubsection{Teacher-Students' and Student-Teacher Engagement Pattern}

From the view of the students, the teacher-students classroom engagement pattern exists during mathematics classroom instruction. The mathematics teacher and the student engaged in profitable discussion initiated by the teacher during classroom talk. This was viewed as good by the student; however some of them felt that the teacher-student engagement pattern still gives the teacher the opportunity to control the learning activities as against the constructivist view of students being the initiator of their learning during classroom instruction [8] [49].

One other engagement pattern discussed under this is the Student-Teacher engagement pattern. From the perceptions of the students, this form of class- 
room engagement pattern should be encouraged during mathematics classroom instruction. This is because, in this pattern of classroom engagement, students initiate the talk, thereby control their learning [50]. Effective classroom instruction should give students the opportunity to control their learning, and also to be self-dependent and responsible for their learning [50] [51]. The constructivist view of teaching and learning particularly in science and mathematics suggest that in this form of interaction, students have the opportunity to defend their thoughts, criticised other students' views and understanding [13] [50]. It increases student's self-efficacy, confidence and improves students' attitude towards mathematics and mathematics problems solving.

\subsubsection{The Teacher-Centred Engagement Pattern}

The findings of the study suggest that this form of classroom engagement was criticised by the students. However, there are researchers that believed the teacher centred interaction could be used in combination with other interactive patterns during classroom instruction. This agrees with the view of Emaliana [52], Acat \& Dönmez [53], Zohrabi et al. [54] who suggested that the teacher centred interaction help teachers have control over the classroom learning and activities. However, the focus group students like most researchers were not in support of this classroom engagement pattern. They believed that students' self-construction of knowledge provides more opportunities for learning than with the teacher centred engagement pattern that had prevailed in most Nigerian classrooms [49].

\subsubsection{Students Individualised Engagement Pattern}

The second classroom engagement pattern observed during the study is the students individualised interaction. According to the study, this could be exhibited in three ways. First, students with high level of mathematics skills tend to prefer individualised engagement pattern with their learning materials alone without the necessary distraction from students of lower ability. This tallies with the views of Ifamuyiwa and Lawani [22] in their discussions on the individualistic engagement patterns, asserted that most students with high ability in Nigerian mathematics classroom prefer working alone without any form of discussions with their classmates. The second group is the group of students with learning challenges. These students tend to be quite in the class without contributing to the development of their classroom learning. The third group is the fearful group, these are mostly observed among the female's students. The fear of being stigmatized or call names, force them to keep quiet during mathematics classrooms instruction [4].

\subsubsection{Student-Student Engagement Pattern}

The findings of the study also suggested that, student-students engagement pattern was observed among the students during the classroom instruction. This form of classroom engagement is one of the best approaches to effective classroom instruction, because students were in charge of their learning with less in- 
terreference from the teacher [13] [51]. From the perceptions of the students, this pattern of engagement assisted them to support one another, particularly the slow learners.

This pattern of classroom engagement helped the students break the jinx of the teacher domineering approach to classroom instruction. The students were able to provide most of the assistance needed by their colleagues [29] [55]. This engagement pattern provided opportunity for student to support their peers as supported in the constructivist perspectives of classroom practice, which believe students come to the class with a level of knowledge and are waiting for the opportunity to put such knowledge into practice if teachers give them the chance [56] [57].

\subsubsection{Whole-Class Engagement Pattern}

The whole class engagement pattern places every member of the class together and the teacher-initiated engagement pattern is demonstrated called the teacher-student engagement pattern. The students appreciated this form of classroom engagement and commented that it brings about cordial relationship between the teacher and the students and it encourages effective discussion during classroom teaching. From my observation, the mathematic teachers at the beginning of the study inform the students that, though, they are working in groups, there is the need for each group to present their findings to the whole class. This is very important as others could learn from the strategies adopted in each group. Findings from the study also suggested that whole class engagement pattern foster effective teacher-student and student-student relationship thereby reducing the teacher-domineering approached to classroom practice [8] [58].

\subsubsection{Group-Based Engagement Pattern}

The findings of the study also suggested that there was the presence of group-based classroom engagement patterns among students during the research. First, the students were able to identify what is called the within-group group engagement patterns as the pattern of engagement where students share ideas, work together, solve problems in small group. From the perception of the students this creates opportunities for students to share ideas in their group [13] [25]. There were also the inter-group engagement patterns, which they defined as the engagement pattern where students seek support from other groups. This engagement pattern can only happen when students within the same group are having challenges within their problem and need the support of their peers instead of their teacher [12] [37]. From observation the mathematics teachers explore these engagement patterns extensively during the study. This help reduced the teacher-centred approach to instruction which is commonly seen in most mathematics classrooms in Nigeria [27] [47].

\subsection{Benefits of Classroom Engagement during Mathematics Classrooms Practice}

The findings of the study suggest that the introducing classroom engagement 
into the Nigerian mathematics classrooms brought about several benefits to students learning and engagement in mathematics classroom practice. From the discussion above most of these benefits have been discussed. Just to mention a few, we shall identify some more benefits that classroom engagement could bring to Nigerian mathematics classroom.

First from the perception of the student's effective classroom engagement makes the learning of mathematics student-centred, increase students' relationship with their teachers, and with other students, makes students take responsibility for their learning and increases students' interest and understanding in mathematics problems solving [3] [11] [23]. The finding also suggests that the student enjoyed this form of classroom instruction because the teachers gave them the opportunity to take charge of their learning, construct their knowledge, defend their views, argued and criticised other students view in an atmosphere of friendship and love [12] [25]. These made the students accountable to their decisions as encouraged in the theory of social constructivism [56] [59].

The findings of the study also suggested that the introduction of classroom engagement among students in the Nigerian mathematics classrooms increases students' self-efficacy, reduces mathematics phobia, anxiety and fear among students. This view served as a possible solution to the fear of mathematics, mathematics anxiety, and mathematics phobia that had eaten deep in the Nigerian students particularly among the secondary school students [3] [4] [11] [60].

\section{Conclusions and Recommendations}

This study was set out to investigate the patterns of classroom engagement in two secondary schools in Northern Nigeria. Four research objectives were postulated to guide the investigation. The qualitative case study approach in a community of practice was adopted to seek information from 12 students for the study. Four preservice teachers were used to teach mathematics in 3 classrooms for a period span across three years. Focus groups, observations, interviews and reflective meetings were the instruments used to seek information for this study.

Several findings were discovered in the study to include the identification of six engagement patterns that were observed among the students during their mathematics classroom practice. Several benefits for introducing classroom engagement patterns were also observed during the classroom practice of the mathematics teachers. Some of which were identified to be effective relation built to mend the already damaged relationship that exists between teachers and their students during classroom instruction. The implementation of classroom engagement practice among students also increases students' self-confidence, self-efficacy and the self-generation of knowledge as against the monopolistic epistemology where the teacher is in charge of all learning in the Nigerian mathematics classroom.

It is therefore recommended that this study is important to teachers and students; particularly teachers that still indulge in the teacher-centred classroom 
approach, should have a rethink, by creating classrooms where students will generate their knowledge and be engaged in profitable discussions about their thoughts on how to solve their classroom problems. It is recommended that creating classrooms that encourage student's engagement help in managing the negative attitude of students to mathematics. The presence of mathematics anxiety and phobia that had frustrated students' engagement in mathematics can also be managed. Classroom instruction is relaxed to allow students engagement during classroom practice. Finally, it is recommended that, further investigation could be carried out with the mathematics teachers to investigate their perceptions of creating classrooms that encouraged engagement among students during mathematics classroom practice.

\section{Conflicts of Interest}

The author declares no conflicts of interest regarding the publication of this paper.

\section{References}

[1] Bature I.J. (2020) The Mathematics Teachers Shift from the Traditional Teacher-Centred Classroom to a More Constructivist Student-Centred Epistemology. Open Access Library Journal, 7, e6389. https://doi.org/10.4236/oalib.1106389

[2] Emaikwu, S.O. (2012) Assessing the Relative Effectiveness of Three Teaching Methods in the Measurement of Students' Achievement in Mathematics. Benue, Nigeria. Journal of Emerging Trends in Educational Research and Policy Studies, 3, 479-486.

[3] Bature, I.J. and Atweh, B. (2019) Collaboration: A Collective Bargain for Achieving Quality Mathematics Classroom Practice. International Journal of Educational Methodology, 5, 347-361. https://doi.org/10.12973/ijem.5.3.347

[4] Bagger, A. and Roos, H. (2015) How Research Conceptualises the Student in Need of Special Education in Mathematics. Development of Mathematics Teaching: Design, Scale, Effects. Proceeding of MADIF 9: The 9th Swedish Mathematics Education Research Seminar Umeå, Linköping, February 4-5, 2014, 27-36.

[5] Dele-Ajayi, O., Strachan, R., Alison Pickard, A. and Sanderson, J. (2019) Games for Teaching Mathematics in Nigeria: What Happens to Pupils' Engagement and Traditional Classroom Dynamics? IEEE Access, 7, 53248-53261. https://doi.org/10.1109/ACCESS.2019.2912359

[6] Bature, I.J. and Igwe, O. (2010) An Investigation into the Factors Affecting Junior Secondary School Three Students Understanding of Mathematics Language in Gombe Metropolis. African Journal of Educational Research and Administration, 3, 47-52.

[7] Bagger, A. and Roos, H. (2020) The Shared Duty of Special Educational Support in Mathematics: Borders and Spaces in Degree Ordinances for Pre-Service Teachers. Educational Springer, Berlin. https://doi.org/10.1007/978-3-030-44292-7_7

[8] Bature, I. and Jibrin, A. (2015) The Perception of Preservice Mathematics Teachers on the Role of Scaffolding in Achieving Quality Mathematics Classroom Instruction. International Journal of Education in Mathematics Science and Technology, 3, 275-287.

[9] Seah, W.T. (2018) Improving Mathematics Pedagogy through Student/Teacher Va- 
luing: Lessons from Five Continents. In: Kaiser, G., Forgasz, H., Graven, M., Kuzniak, A., Simmt, E. and Xu, B., Eds., Invited Lectures from the 13 th International Congress on Mathematical Education, Springer International, Cham, 561-580. https://doi.org/10.1007/978-3-319-72170-5_31

[10] Abah, J., Anyagh, P. and Age, T. (2017) A Flipped Applied Mathematics Classroom: Nigerian University Students' Experience and Perceptions. Mathematics Education Series, 42, 78-87.

[11] Bature, I.J. and Atweh, B. (2016) Achieving Quality Mathematics Classroom Instruction through Productive Pedagogies. International Journal of Educational Methodology, 2, 1-18. https://doi.org/10.12973/ijem.2.1.1

[12] Bature I.J., Atweh, B. and Treagust, D (2016) Inclusivity: An Effective Tool for Achieving Quality Mathematics Classroom Instruction in Nigerian Secondary Schools. Universal Journal of Educational Research, 4, 173-180. https://doi.org/10.13189/ujer.2016.040122

[13] Bature, I.J., Atweh, B. and Oreoluwa, F. (2020) Investigating the Perception of Senior Secondary School Students on the Role of Classroom Engagement in Mathematics Problem Solving. Journal of Research in Science, Mathematics and Technology Education, 3, 73-105. https://doi.org/10.31756/jrsmte.323

[14] Sequeira, A.H. (2013) Factors Contributing to Students' Academic Performance. National Institute of Karnataka, Surathkal. Journal of Educational Research, 1, 283-289. https://doi.org/10.12691/education-1-8-3

[15] Acharya, B.B. (2017) Factors Affecting Difficulties in Learning Mathematics by Mathematics Learners. International Journal of Elementary Education, 6, 8-15. https://doi.org/10.11648/j.ijeedu.20170602.11

[16] Berger, R. (2015) Now I See It, Now I Don't: Researcher's Position and Reflexivity in Qualitative Research. Qualitative Research, 15, 219-234. https://doi.org/10.1177/1468794112468475

[17] Bolyan, M. and Woolsey, I. (2016) Teacher Education for Social Justice: Mapping Identity Spaces. Teaching and Teacher Education, 46, 62-71. https://doi.org/10.1016/j.tate.2014.10.007

[18] Okafor, C.F. and Anaduaka, U.S. (2013) Nigerian School Children and Mathematics Phobia: How the Mathematics Teacher Can Help. American Journal of Educational Research, 1, 247-251. https://doi.org/10.12691/education-1-7-5

[19] Seah, W.T. and Andersson, A. (2015) Valuing Diversity in Mathematics Pedagogy through the Volitional Nature and Alignment of Values. In: Bishop, A., Tan, H. and Barkatsas, T., Eds., Diversity in Mathematics Education, Springer, Cham, 167-183. https://doi.org/10.1007/978-3-319-05978-5_10

[20] Humphreys, B., Johnson, R.T. and Johnson, D.W. (1982) Effects of Cooperative, Competitive, and Individualistic Learning on Students' Achievement in Science Class. Journal of Research in Science Teaching, 19, 351-356. https://doi.org/10.1002/tea.3660190503

[21] Okebukola, P.A. and Ogunniyi, M.B. (1984) Cooperative, Competitive, and Individualistic Science Laboratory Interaction Patterns: Effects on Students' Achievement and Acquisition of Practical Skills. Journal of Research in Science Teaching, 21, 875-884. https://doi.org/10.1002/tea.3660210903

[22] Ifamuyiwa, A. and Lawani, A. (2008) Interaction Patterns in Mathematics Classrooms in Ogun State Secondary Schools. The Online Journal, 6, Article: 11.

[23] Bature, I.J., James, J.J., Aramide, K., Danladi, R.S. and Nengak, S. (2015) Introduc- 
ing Productive Pedagogies to Nigerian Mathematics Classroom through Collaborative Action Research Using a Community of Practice Approach. International Journal of Learning, Teaching and Educational Research, 11, 41-58.

[24] Ifamuyiwa, A.S. (2007) Effects of Self and Cooperative Instructional Strategies on Senior Secondary School Students' Learning Outcomes in Mathematics. University of Ibadan, Ibadan.

[25] Bature, I.J. and Atweh, B. (2020) Mathematics Teacher's Reflection on the Role of Productive Pedagogies in Improving Their Classroom Instruction. International Journal of Educational Methodology, 6, 319-335. https://doi.org/10.12973/ijem.6.2.319

[26] Sullivan, P. (2018) Challenging Mathematical Tasks: Unlocking the Potential of All Students. OUP Oxford, Oxford.

[27] Bature, I.J. and Bundot, G.B. (2009) Setting the Classroom Climate for Effective Teaching and Learning Process: Implications for Classroom Environment and Learning. International Journal for Contemporary Issues in Education, Special Edition, 198-201.

[28] Anthony, G. and Walshaw, M. (2009) Effective Pedagogy in Mathematics. International Bureau of Education, Geneva.

[29] NERDC (2013) Lesson Planning Based on Modern Teaching Approaches (For Mathematics). Nigerian Educational Research and Development Council Sheda, Bulleting Released, 5 June 2013.

[30] Atweh, B. (2013) Beyond Student Centred Learning: Towards Socially Response-Able Mathematics Education. Keynote Presentation at Columbia University.

http://oneworldripples.com/uploads/3/2/1/3/3213041/keynote_address_colombia_a tweh.pdf

[31] Clarke, D. (2010) Speaking in and about Mathematics Classrooms Internationally: The Technical Vocabulary of Students and Teachers. https://research.acer.edu.au/research_conference/RC2010/16august/2

[32] Clarke, D.M. and Roche, A. (2009) Opportunities and Challenges for Teachers and Students Provided by Tasks Built around "Real" Contexts. In: Hunter, R., Bicknell, B. and Burgess, T., Eds., Crossing Divides. Proceedings of the 32 nd annual conference of the Mathematics Education Research Group of Australasia, Palmerston North, 5- 9 July 2009, 722-726.

[33] Sullivan, J.V. (2018) Learning and Embodied Cognition: A Review and Proposal. Psychology Learning \& Teaching, 17, 128-143. https://doi.org/10.1177/1475725717752550

[34] National Council of Teachers of Mathematics (2014) Principles to Actions: Ensuring Mathematical Success for All. National Council of Teachers of Mathematics, Reston.

[35] Boston, M.D. (2012) Assessing Instructional Quality in Mathematics. Elementary School Journal, 113, 76-104. https://doi.org/10.1086/666387

[36] Smith, M.S. and Stein, M.K. (2011) 5 Practices for Orchestrating Productive Mathematical Discussions. National Council of Teacher of Mathematics, Reston.

[37] Sullivan, P., Askew, M., Cheeseman, J., Clarke, D., Mornane, A., Roche, A. and Walker, N. (2015) Supporting Teachers in Structuring Mathematics Lessons Involving Challenging Tasks. Journal of Mathematics Teacher Education, 18, 123-140.

[38] Bature, I.J. and Zuya, E. (2008) The Mathematics Teachers' Classroom Environment: A Case of Concerned to Secondary School Mathematics Teaching and 
Learning. Journal of Technology Education, 1, 104-116.

[39] Abimbade, A. and Afolabi, S.S. (2012) A Study of Pedagogical Approaches of Mathematics Teaching in South-Western States of Nigeria. International Journal of Asian Social Science, 2, 1182-1192.

[40] Baxter, P. and Jack, S. (2008) Qualitative Case Study Methodology: Study Design and Implementation for Novice Researchers. The Qualitative Report, 13, 544-559.

[41] Clandinin, D.J. and Connelly, F.M. (2000) Narrative Inquiry: Experience and Story in Qualitative Research. Jossey-Bass, San Francisco, CA.

[42] Caulfield, J. (2019) How to Do Thematic Analysis. https://www.scribbr.com/methodology/thematic-analysis/

[43] Creswell, J.W. (2014) Research Design: Qualitative, Quantitative and Mixed Methods Approaches. 4th Edition, Sage, Thousand Oaks, CA.

[44] Carter, M.J. and Fuller, C. (2016) Symbols, Meaning, and Action: The Past, Present, and Future of Symbolic Interactionism. Current Sociology, 64, 931-961. https://doi.org/10.1177/0011392116638396

[45] Evers, J.C. (2016) Elaborating on Thick Analysis: About Thoroughness and Creativity in Qualitative Analysis. Qualitative Social Research, 17, Article No. 6.

[46] Brophy, J.E. (2006) History of Research in Classroom Management. In: Evertson, C. and Weinstein, C., Eds., Handbook of Classroom Management. Research, Practice, and Contemporary Issues, 17-43.

[47] Attard, C. (2013) Introducing Ipads into Primary Mathematics Pedagogies: An Exploration of Two Teachers' Experiences. Mathematics Education: Yesterday, Today and Tomorrow. Proceedings of the 36th Annual Conference of the Mathematics Education Research Group of Australasia, Melbourne, 7-11 July 2013, 58-65.

[48] Hall, J.J. and Sink, C.A. (2015) Nature of Mathematics Classroom Environments in Catholic High Schools. Journal of Catholic Education, 18, 73-98.

https://doi.org/10.15365/joce.1802052015

[49] Kalogeropoulos, P. and Bishop, A.J. (2017) What Is the Role of Value Alignment in Engaging Mathematics Learners? In: Chronaki, A., Ed., Proceedings of the 9 th International Mathematics Education and Society Conference, Volos, 7-12 April 2017, 603-610.

[50] Kalogeropoulos, P. (2016) The Role of Value Alignment in Engagement and (Dis) Engagement in Mathematics Learning. Monash University, Melbourne.

[51] Bada, S.O. (2015) Constructivism Learning Theory: A Paradigm for Teaching and Learning. Journal of Research \& Method in Education, 5, 66-70.

[52] Emaliana, I. (2017) Teacher-Centered or Student-Centered Learning Approach to Promote Learning? Journal Sosial Humaniora, 10, 59-70.

[53] Acat, B. and Dönmez, İ. (2009) To Compare Student Centered Education and Teacher Centered Education in Primary Science and Technology Lesson in Terms of Learning Environments. Procedia-Social and Behavioral Sciences, 1, 1805-1809. https://doi.org/10.1016/j.sbspro.2009.01.320

[54] Zohrabi, M., Torabi, M.A. and Baybourdiani, P. (2012) Teacher-Centered and/or Student-Centered Learning: English Language in Iran. English Language and Literature Studies, 2, 18-30. https://doi.org/10.5539/ells.v2n3p18

[55] Chronaki, C.E. (2016) Mathematics Education as a Matter of Identity. In: Peters, M.A., Ed., Encyclopedia of Educational Philosophy and Theory, Springer Nature, Singapore, 1-6. https://doi.org/10.1007/978-981-287-532-7_517-1

[56] Anderson, A., Hinz, B. and Matus, H. (2017) The Paradigm Shifters: Entrepreneuri- 
al Learning in Schools. Mitchell Institute, Melbourne.

[57] Fisher, D. and Frey, N. (2013) Better Learning through Structured Teaching: A Framework for the Gradual Release of Responsibility. 2nd Edition, ASCD, Alexandria.

[58] Sullivan, P. and Mornane, A. (2014) Exploring Teachers' Use of, and Students' Reactions to, Challenging Mathematics Tasks. Mathematics Education Research Journal, 26, 193-213. https://doi.org/10.1007/s13394-013-0089-0

[59] Hattie, J.A.C. (2009) Visible Learning: A Synthesis of over 800 Meta-Analyses Relating to Achievement. Routledge, London, 392.

https://doi.org/10.4324/9780203887332

[60] Bucholz, J.L. and Sheffler, J.L. (2009) Creating a Warm and Inclusive Classroom Environment: Planning for All Children to Feel Welcome. Electronic Journal for Inclusive Education, 2, 1-13. 